\title{
A new online tool to improve physician billing
}

I f you do the work, you might as well get paid for it. Many doctors, however, are not receiving compensation they are entitled to, thanks to the complexities of billing for medical services in Canada.

"We run into this all the time," said D'Arcy Shade, technical advisor of physician payments for the Alberta Medical Association (AMA). "There have been some sad cases where physicians have walked away from a lot of money."

The problem can be summarized in three letters: PDF. Each province has a schedule of benefits for medical services - sprawling and complex PDF documents with more numbers than a footthick phonebook. Ontario's schedule is 750 pages long. Alberta has multiple documents - one for explanatory codes, one for fee modifier definitions, one for medical government rules and others - and the price list alone comes in at a hefty 776 pages.

"It can be an overwhelming and confusing document," said Shade.

To make billing less painful and more accurate, Alberta has created an online, mobile-friendly, easy-to-use tool called the AMA Fee Navigator. It is an educational tool intended to

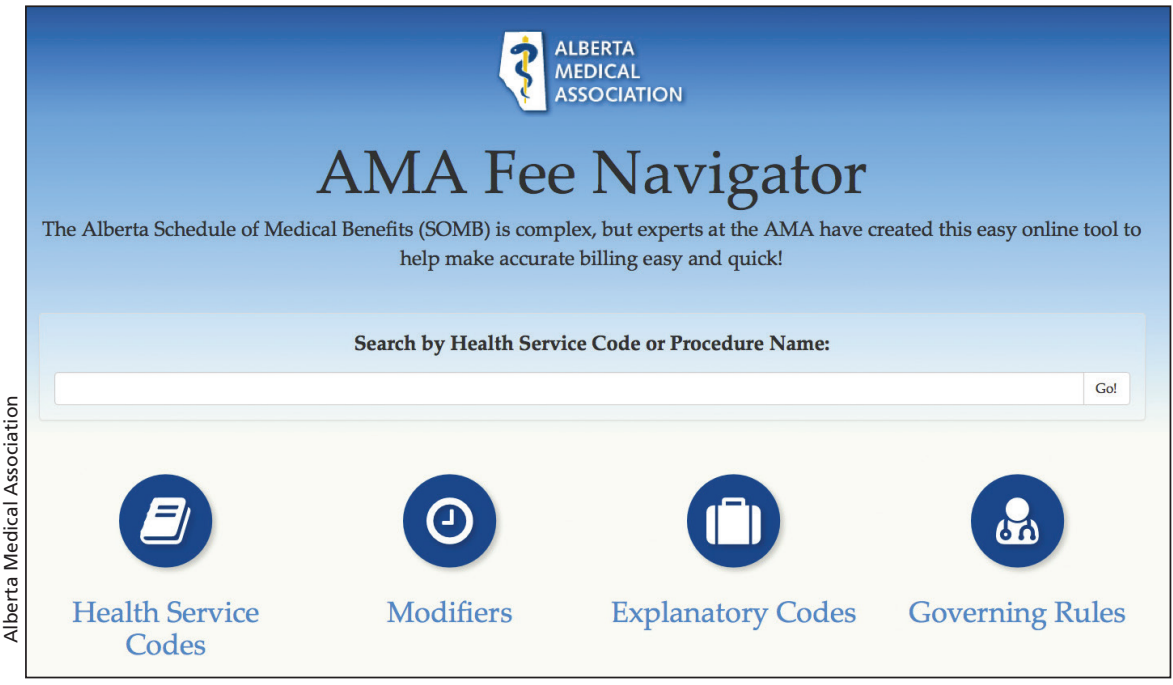

The AMA Fee Navigator allows users to search by a procedure's name or code.

set fee. But a physician who treats a patient with a body mass index over 35 for a compound fracture at $11 \mathrm{pm}$ on a Friday night is entitled to more.

Shade also hopes AMA Fee Navigator will decrease incorrect billings. After all, if inadvertent errors lead to an audit, it is ultimately the physician, not clerical staff, who will be held responsible.

The AMA Fee Navigator has already gained notice in other parts of Canada. Doctors Nova Scotia, for one,

\section{"There have been some sad cases where physicians have walked away from a lot of money."}

demystify the entire process, allowing users to search by a procedure's name or code. It also offers advice, tips and up-to-date billing information.

So far, the website has proven popular and feedback has been overwhelmingly positive, said Shade. There have been comments from medical residents about how useful it is, probably because, like most doctors, they have little if any formal training in billing. Even experienced billing clerks can make mistakes.

One common mistake, for example, is billing for only the base fee when several modifiers apply to a particular medical service. A physician who treats a patient for a fracture is entitled to a is "very interested" in the tool, according to Derek Law, director of compensation and negotiations for the association. "Currently, we do not have such a tool but definitely see value in such a tool," he wrote in an email. "We will be investigating it further."

Doctors Nova Scotia hopes to learn from Alberta to help its physicians improve their billing practices and reduce errors, added Kim Bottomley, a communications advisor for the association. The province has already made efforts to improve billing, such as offering educational sessions and modernizing the Nova Scotia Medical Services Insurance Physician's Manual.
"While we have made great strides in improving the billing landscape for physicians, there is much more work to do and more improvements needed for this outdated, cumbersome and often confusing process," Bottomley wrote in an email.

According to Shade, no other province yet offers an online tool like the AMA Fee Navigator. Doctors of BC, however, does have a popular online fee guide, accessible only to members, with information not contained in the Medical Services Plan Payment Schedule.

"Doctors find the online fee guide to be extremely beneficial as it is a quick and easy source of billing information containing a searchable list of MSP [Medical Services Plan] fees and billing rules, individual section breakdowns and the fee guide preamble," read a statement attributed to Dr. Charles Webb, the association's president. "The online fee guide is well used by doctors and is among the top 10 reasons why doctors visit the Doctors of BC website." - Roger Collier, CMAJ

CMAJ 2015. DOI:10.1503/cmaj.109-5120

\section{More News online}

To read more CMAJ news articles, visit cmaj.ca/site/home/news.xhtml 